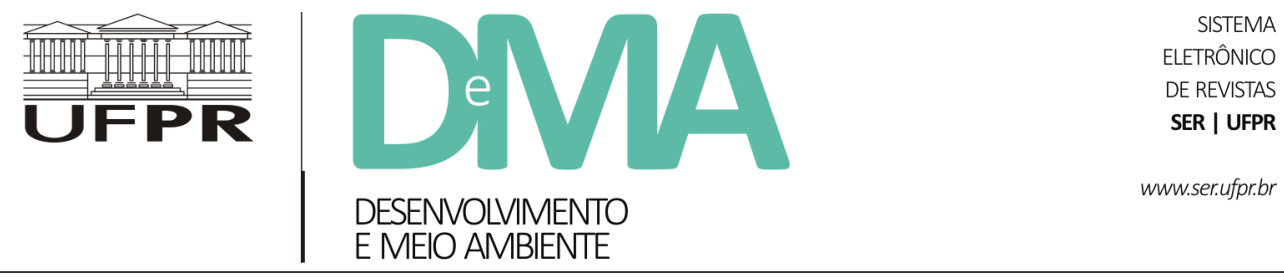

\title{
Mineração, impactos locais e os desafios da diversificação: revisitando Itabira
}

\section{Mining, Local Impacts and the Challenges of Diversification: Revisiting Itabira}

\author{
Carolina Lucinda GUIMARÃES ${ }^{1}$, Bruno MILANEZ ${ }^{1 *}$ \\ ${ }^{1}$ Universidade Federal de Juiz de Fora (UFJF), Juiz de Fora, MG, Brasil. \\ *E-mail de contato: bruno.milanez@ufjf.edu.br
}

Artigo recebido em 22 de novembro de 2016, versão final aceita em 26 de junho de 2017.

RESUMO: Neste texto, argumenta-se que, no contexto brasileiro, a mineração de grande escala gera significativos impactos ambientais e consideráveis desafios à dinamização da economia local. Este argumento, é apresentado a partir de estudo de caso em Itabira (MG); a pesquisa identifica sérios problemas ambientais e sociais na cidade, além de dificuldades estruturais da promoção de políticas de diversificação econômica e de superação da dependência da atividade de extração mineral. A pesquisa foi realizada a partir de levantamento bibliográfico e entrevistas semi-estruturadas com informantes-chave. Ela trata da história de Itabira, a instalação da Companhia Vale do Rio Doce (CVRD), assim como aspectos sociais e econômicos do desenvolvimento local. O estudo sugere que existem questões econômicas, inerentes ao setor extrativista, que limitam o surgimento e consolidação de outros setores. Assim, entender em maior profundidade a dinâmica econômica de cidades do Quadrilátero Ferrífero torna-se imperativo para debater a superação do modelo baseado em extração mineral na região.

Palavras-chave: mineração; desenvolvimento local, diversificação econômica.

ABSTRACT: In this paper, it is argued that, in the Brazilian context, large-scale mining generates significant environmental impact and considerable challenges to the dynamization of the local economy. The argument is based on a case-study on Itabira (MG); the research indicates serious local environmental and social problems, in addition to structural difficulties in promoting policies for economic diversification and in overcoming its economic dependence on the mining sector. The research is based on literature review and semi-structured interviews with key-informants. It considers the history of Itabira, the installation of the Companhia Vale do Rio Doce (CVRD), as well as social and economic aspects of the local development. The study suggests there are economic issues intrinsic to the extractive sector that restrict the flourishing and consolidation of other sectors. Therefore, a deeper understanding of the economic dynamics of the Quadrilátero Ferrífero region becomes imperative to debate the overcoming of a development model based on mineral extraction.

Keywords: mining; local development; economic diversification. 


\section{Introdução}

O objetivo principal desta pesquisa consiste em avaliar, sob diferentes perspectivas, a contribuição da atividade extrativa mineral em larga escala para o desenvolvimento local no contexto brasileiro. Ao buscar esse objetivo, argumenta-se que tal atividade gera significativos impactos sociais e ambientais, não necessariamente mitigados de forma efetiva pelos sistemas de gestão ambiental, além de criar desafios significativos à dinamização da economia local, não garantindo a redução da dependência econômica das atividades extrativas.

A pesquisa, de caráter indutivo, é baseada em um estudo de caso único (Yin, 2005). Os métodos para realizar o estudo se basearam na coleta e análise de dados primários e secundários. $\mathrm{O}$ estudo se iniciou com o levantamento bibliográfico e análise documental. A partir dessas informações, realizou-se um trabalho de campo em março de 2015, onde foram realizadas entrevistas semi-estruturadas com informantes-chaves ${ }^{1}$.

O estudo de caso é baseado no município de Itabira. A cidade foi escolhida por ter sido o primeiro centro no país de extração mineral em grande escala para exportação, com a implantação da Companhia Vale do Rio Doce (CVRD), na década de 1940. Assim, pode ser caracterizada como exemplo emblemático do modelo minero-exportador, que vem sendo amplamente adotado em diferentes cidades em Minas Gerais, Pará e Goiás, por exemplo. Além disso, como o município se localiza em Minas Gerais, estado com significativa capacidade de planejamento e implementação de políticas públicas, parte-se do pressuposto de que ele seria um local favorável para se verificar o uso dos recursos oriundos da extração mineral na construção de políticas efetivas de controle ambiental e dinamização econômica. Entretanto, o levantamento feito sugere sérios problemas ambientais e sociais na cidade, além de dificuldades estruturais da construção de políticas de diversificação econômica e de superação da dependência da atividade de extração mineral.

$\mathrm{O}$ texto encontra-se organizado em seis partes, além desta introdução. A seção 2 consiste em uma proposta de sistematização das perspectivas desenvolvidas por diferentes áreas de conhecimento sobre a extração mineral. A terceira seção apresenta uma contextualização inicial de Itabira, descrevendo alguns aspectos gerais e, principalmente, a relação que foi criada entre a companhia e a cidade. A seção 4 trata de impactos socioambientais que, no caso de Itabira, são associados à grande mineração. Ela incorpora a questão da mudança da paisagem e a poluição atmosférica, principalmente na área urbana. Para além de mudanças no meio físico, esta seção trata de questões relativas à saúde mental da população, focando no debate sobre o índice de suicídios na cidade. Na seção 5, comenta-se sobre a reação da sociedade e das instituições em relação aos impactos da mineração, destacando-se a limitada capacidade que possuem para fazer frente à expansão mineral. A seção 6, por sua vez, aborda a mineração a partir de uma perspectiva econômica, debatendo as limitações do planejamento econômico da cidade devido à sua dependência da receita volátil do minério, bem como as dificuldades enfrentadas para tentar reduzir tal dependência. Por fim, na seção 7, apontam-se as

${ }^{1}$ Apesar de contatados em diferentes momentos, representantes da Vale S.A. não aceitaram participar da pesquisa. 
principais lições aprendidas a partir da observação do caso de Itabira.

\section{Debates sobre mineração, meio ambiente, economia e sociedade}

A literatura científica apresenta uma ampla e diversa produção sobre o tema da extração mineral. Tais estudos vêm sendo realizados a partir de diferentes áreas de conhecimento; porém, comumente pode ser identificado um certo grau de polarização entre uma leitura normativa sobre o potencial positivo da atividade de extração mineral e outra crítica em relação aos efeitos da mineração.

Do ponto de vista do meio físico e do consumo dos recursos naturais, as pesquisas mostram uma certa vinculação metodológica aos estudos de impacto ambiental, bem como associação às práticas de gestão ambiental. Dentro desse campo, existem estudos que tentam identificar os impactos ambientais associados à extração mineral e recomendar novas tecnologias, ou boas práticas empresariais que busquem mitigar alguns desses impactos (Caron et al. 2016; Laurence, 2011). Por outro lado, há estudos que questionam essa postura otimista e se propõem não apenas a listar os impactos ambientais da extração mineral, como ainda explicitar as limitações das propostas tecnológicas comumente usadas pelas empresas (ELAW, 2010; Gudynas, 2015; Whitmore, 2006).

Outro campo, que vem sendo amplamente expandido, diz respeito às resistências das comunidades à implantação de grandes projetos minerários, bem como as estratégias e instrumentos que as empresas mineradoras desenvolvem para inibir ou confrontar essa contestação. O primeiro grupo de estudos é vinculado - principalmente - às áreas da sociologia, antropologia e geografia (Ballard \& Banks, 2003; Bebbington \& Bury, 2014; Kirsch, 2014; Santos \& Milanez, 2015); já o segundo grupo, se relaciona à gestão empresarial, planejamento estratégico e responsabilidade social corporativa (Rajak, 2011; Sagebien \& Lindsay, 2011).

A terceira área, onde talvez exista maior tradição em pesquisa, está relacionada aos aspectos econômicos da atividade mineral. Nesse campo, Davis \& Tilton (2005) organizam a literatura em "visão convencional" e "visão alternativa".

A visão convencional é aquela que defenderia a extração mineral como um caminho de crescimento econômico e, até mesmo, de desenvolvimento para os países pobres. Ela é defendida tanto por órgãos multilaterais, como o Banco Mundial (Sinnott et al., 2010), quanto por institutos de formulação de políticas ligados a agências de desenvolvimento (NGRI, 2015). Dentro dessa interpretação, problemas econômicos vinculados ao desenvolvimento baseado em recursos minerais seriam mais uma questão de boa governança e capacidade institucional do que um elemento inerente ao setor (Davis \& Tilton, 2005).

Do outro lado, existiriam análises econômicas - principalmente vinculadas ao conceito da maldição dos recursos naturais. De acordo com essa perspectiva, a elevada dependência das economias nacionais de recursos naturais, principalmente do ponto de vista das exportações, poderia ser associada a uma menor taxa de crescimento. Esse processo seria inerente ao setor extrativo mineral e se relacionaria com a deterioração dos termos de troca, com a elevada volatilidade dos preços dos recursos minerais no mercado internacional, com a falta de encadeamento das atividades extrativas 
e com a formação de enclaves econômicos (Auty, 2001; Gamu et al., 2015; Power, 2002).

Dessa forma, estudos sobre mineração podem se dar a partir de diferentes áreas de conhecimento e sob diferentes perspectivas. Na presente pesquisa, alguns desses aspectos são abordados ao se estudar a relação da Vale com a cidade de Itabira.

\section{A cidade, a empresa e a mineração}

A cidade de Itabira, localizada no interior de Minas Gerais, próxima à capital, Belo Horizonte, é tradicionalmente conhecida pela extração de minério, pela origem da Vale S.A. (antiga CVRD) e por ser a terra natal do poeta Carlos Drummond de Andrade. A ocupação da região começou no final do século XVII, tendo como base a agricultura e a pecuária de subsistência. A partir do século XVIII, houve um grande fluxo migratório motivado pela descoberta do ouro que, entretanto, mostrou-se insuficiente para garantir um desenvolvimento duradouro (Faria \& Andrade, 1959).

No século XX, teve início a exploração de minério de ferro. Esse processo foi iniciado a partir da pequena produção, principalmente para atender a necessidades de siderúrgicas locais. Em 1910, foram encontradas importantes jazidas de minério de ferro, que resultaram na criação do Brazilian Hematite Syndicate por engenheiros ingleses. No ano seguinte, foi criada a Itabira Iron Ore Company, com permissão do Governo Federal, visando a extração e exportação do minério. Para tanto, a empresa deveria assumir a expansão e a operação da Estrada de Ferro Vitória a Minas (EFVM), de forma a garantir o escoamento do minério extraído (Enríquez, 2007; Presas, 2012; Saraiva, 2012).
Entretanto, o projeto enfrentou diferentes dificuldades devido à insuficiência de capital e a pressões de grupos nacionalistas, que defendiam que a exploração deveria ser feita por empresas nacionais. Durante a Segunda Guerra Mundial, o governo dos Estados Unidos da América propôs ao Brasil que a exploração do minério de ferro suprisse a fabricação de armamentos para os Aliados. Para tanto, em 1942, foi criada a Companhia Vale do Rio Doce (Enríquez, 2007, Saraiva, 2012).

A implantação e o desenvolvimento da Vale, transformaram profundamente o modo de vida do itabirano. O município (que antes vivia da confecção de tecidos, agricultura e pecuária) passou, de forma crescente, a depender de uma única atividade - a mineração - e de uma única empresa - a Vale. As mudanças não se restringiram apenas ao aspecto econômico, mas à própria forma de se viver em Itabira.

Itabira, antes da mineração, como outras cidades tradicionais de Minas Gerais, sempre possuiu uma cultura própria e marcante, que foi imposta às pessoas que chegavam ao município. As novas ideias, relacionadas à literatura e às artes em geral, foram sendo implantadas aos poucos pelos filhos das famílias tradicionais da cidade, que saíam de Itabira para obter formação nos colégios célebres da época e, ao concluir seus estudos, retornavam ao município. A cidade também se destacou por seus muitos clubes, restritos apenas à elite local, e grande apreço por esportes. A partir desse contexto, Presas (2012) classifica o itabirano como um povo conservador e elitista.

As mudanças causadas pela chegada da empresa geraram uma diversidade de opiniões. Muitos a encararam, inicialmente, como o início de um processo de dominação inevitável, uma apropriação 
de seu espaço e houve, assim, um sentimento de perda. Esse sentimento, de certa forma, era mais forte nas famílias mais ilustres. Presas (2012) menciona que, até a década de 1960, não havia filhos das famílias tradicionais de Itabira trabalhando na Vale, sendo isso visto como uma humilhação. Segundo a autora, era preferível envelhecer sem trabalhar a se "vender" à mineração. Ao mesmo tempo, Carlos Drummond de Andrade, outro membro ilustre da sociedade itabirana, expressou, ao longo de sua obra, sua aversão às mudanças que a mineração $\mathrm{e}$ a Vale trouxeram à cidade (Frochtengarten, 2004).

Presos às suas tradições, alguns itabiranos abriram mão das oportunidades proporcionadas pela exploração do minério. Embora se opusessem à fonte de renda associada à mineração, segundo Saraiva \& Carrieri (2012), adquiriram as qualidades do ferro, tornando-se rígidos e frios.

"Existe essa formação arcaica, então assim, o itabirano é muito acomodado. Ele vê ou tem um pessimismo relativo que não vai dar certo. Essa realidade de três anos para cá tem mudado bastante, porque, principalmente dos jovens até os trinta, você vê o roteiro cultural, roteiro de bares, de entretenimento, então as pessoas estão tomando coragem" (Silva, 2015).

No entanto, a possibilidade de emprego e os elevados salários atraíram muitos trabalhadores, qualificados ou não, da região rural, assim como de outras cidades. Os "forasteiros" (como os itabiranos chamavam os migrantes), principalmente os vindos de Santa Maria de Itabira, encararam Itabira como uma "terra de oportunidade", e não apenas buscavam empregos na mineração como começaram a abrir pequenos negócios, até o ponto de controlar o comércio local (Presas, 2012).

Esta mudança resultou na alteração da pirâmide social, uma vez que a mineradora passou a contratar e pagar bons salários para a, até então, classe baixa. Ao mesmo tempo, foi se formando uma nova burguesia, composta pelos pequenos comerciantes. Assim, Itabira cresceu junto com a Vale: sua população aumentou significativamente, de 11.492 pessoas na década de 1940 (Bastos, 2008) para uma população estimada de $117.634 \mathrm{em} 2015$ (IBGE, 2016).

Assim, a mineradora viabilizou o acesso às riquezas naturais, e parte da renda capturada facilitou o crescimento do município. Ao longo dos anos, a empresa, principalmente na fase "mãe", não gerou apenas bem-estar, mas criou também uma situação de comodismo e dependência. Uma das consequências desse processo foi a redução das críticas feitas à mudança em geral e à empresa em particular. De forma geral, a "modernização" gerada pela Vale alterou - significativamente - o patrimônio cultural da cidade, havendo pouca resistência social a esse processo.

"É instigante o apoio do poder público e da sociedade local ao processo de desconfiguração e reconfiguração do centro histórico, mesmo que esse processo tenha ocorrido em detrimento da paisagem simbólica da cidade. De certa maneira, há conivência da população e da administração municipal na destruição do patrimônio público/cultural e simbólico da cidade. Não há, nessa época, em Itabira e em outros lugares, consciência da importância de se preservarem esses imóveis. Tudo é justificado pela ideia e sentimento do progresso presentes naquele momento e ainda [...]

\footnotetext{
${ }^{2} \mathrm{Na}$ literatura que descreve a relação da Vale com a comunidade de Itabira é comum encontrar referências à "Vale mãe", durante o período em que empresa era estatal, e a "Vale madrastra" após a privatização (cf. Enríquez, 2007; Presas, 2012).
} 
a água usada no processo de beneficiamento do minério e as das chuvas precipitadas nas minas carregam rejeitos que se depositam a jusante dessas, formando imensas áreas assoreadas, muitas vezes localizadas próximas a bairros. Para conter os rejeitos, a CVRD constrói barragens de contenção que assoreiam, destroem estradas, vales, solos agricultáveis, área rurais e urbanas" (Silva, 2004, p. 95-96).

Assim, a construção e o crescimento da Vale se deram durante uma longa história. Presas (2012) a divide em três etapas: a pública nacionalista (1942 - 1967), pública internacionalista (1965 - 1996) e privada mercadológica (1997 aos dias atuais).

Durante a primeira fase, a Vale foi associada a um projeto nacional-desenvolvimentista, sob grande intervenção do Governo Federal e, teoricamente, associada à necessidade de minério de ferro para o desenvolvimento de projetos siderúrgicos nacionais. Nesse momento, a Vale foi concebida como uma empresa "dos brasileiros e para os brasileiros" (ibidem, p. 117), responsável não apenas pelo desenvolvimento do país, mas também dos territórios onde se localizava. Durante essa fase, de acordo com seu estatuto, a empresa destinava cerca de $8 \%$ do seu lucro líquido para projetos de desenvolvimento socioeconômico nas suas áreas de atuação.

Segundo a autora, esse período foi marcado por benefícios relacionados à educação, saúde e habitação. No caso da habitação, particularmente, a empresa se caracterizava por um tratamento elitista, separando seus trabalhadores do resto da cidade - e ainda dividindo os trabalhadores entre si. Nessa mesma época, a empresa construiu dois núcleos habitacionais, próximos às minas, para acomodar os seus empregados. Dessa forma, os funcionários da Vale já se diferenciavam dos demais itabiranos.
Entretanto, havia diferenças entre os padrões desses núcleos. Os funcionários que ocupavam cargos mais baixos foram para um núcleo com construções mais simples, enquanto aqueles que possuíam cargos altos, para um mais sofisticado. Naquele momento, essa prática distinguia os funcionários da Vale segundo critérios prestigiosos, reforçando a imagem de empresa provedora. Assim, durante essa fase, a empresa adquiriu legitimidade em Itabira e criou a noção da "mãe Vale".

O segundo período, proposto por Presas (2012), se relaciona com as mudanças políticas no país, com a tomada do poder pelos militares e, posteriormente, pela redemocratização política. Naquele momento, a empresa teria reduzido seu enfoque no abastecimento do mercado interno para concentrar suas energias na exportação de minério. De certa forma, essa mudança de enfoque levou a alterações na gestão da empresa, levando a uma crescente preocupação com o profissionalismo e com os resultados.

A consolidação dessa transformação se deu, em 1997, com a privatização. A partir do aprofundamento nas políticas neoliberais no país, a empresa passou por um processo de reestruturação, buscando aumento de produtividade e redução de gastos. Isso impactou Itabira diretamente, com a redução dos investimentos na cidade, e indiretamente, com cortes de postos de trabalho, programas de demissão voluntária e aumento da terceirização. Esse aprofundamento no modelo de gestão, baseado na "eficiência", abalou a relação da comunidade com a empresa; a partir de então, a mãe, passou a ser conhecida como "Madrasta Vale" (Enríquez, 2007; Presas, 2012).

A mudança do cenário "Mãe Vale" para o de "Madrasta Vale" foi sentida tanto pelos funcionários 
da mineradora, quanto pelos itabiranos em geral. Em entrevista realizada no município de Itabira, com a então coordenadora de projetos da FUNCESI, Flávia Martins Guerra Pantuza, tal situação foi mencionada:

"Eu acho que vocês já até acompanharam um pouco, porque, em 1997, houve a privatização, né? E aí a mudança de visão, né? E, aí, a mudança de procedimentos, uma estatal numa cidade desta é, tinha uma diretoria, com muitas mordomias, né? Era motorista pra levar pro balé, tinha gente que... ah, vai pra Belo Horizonte pro balé, pro inglês, entendeu? Aí, muda, né? Essa relação da empresa e eles falavam que a Vale era uma mãe, eu escutei muito isso aqui (risos), a Vale é uma mãe, e aí ela passou a ser madrasta, né? Então, a relação mudou, aquela visão é, era muito assistencialista, tudo que o município queria... era fazer um parque não sei onde, né? Quer fazer... e essa relação, ela muda a partir da privatização, principalmente, né? É, e aí é focada a empresa, né? Hoje é pior, né? Porque é empresa, e é acionista, e é banco, né? Então, assim, a visão é focada em resultados, é de pressão, é então a realidade de hoje é um cenário bem diferente, existe na população, a gente percebe, uma certa mágoa, né?" (Pantuza, 2015).

Ao final desse processo, a Vale se consolidou como uma das maiores mineradoras do mundo.

"Na realidade, (a Vale) é um poder paralelo no país, não é? Multinacional, está em 18 estados brasileiros, 30 países, cinco continentes. E tudo começou aqui [em Itabira], em 1942, vocês estão vendo aí" (Ferreira, 2015).

A empresa possui não apenas importantes minas no Brasil e no exterior, como ainda uma ampla rede logística, incluindo ferrovias, portos, navios mineraleiros e super mineraleiros. Seu crescimento, ao mesmo tempo, passou a ter forte influência na cidade de Itabira. Por um lado, ela foi um dos principais indutores de mudanças econômicas, sociais, culturais e ambientais. Por outro, um crescimento ausente de críticas efetivas permitiu que ocorresse a perda de patrimônio simbólico, a degradação ambiental, a poluição atmosférica e os impactos sobre a saúde, conforme discutido na próxima seção.

\section{Impactos socioambientais}

\subsection{Mudanças na paisagem}

Um dos impactos mais visíveis em Itabira é a mudança na paisagem, particularmente em relação à destruição do pico do Cauê. Saraiva \& Carrieri (2012) narram que, segundo seus entrevistados, antes da chegada da Vale, a cidade amanhecia às onze horas, devido ao morro do Cauê, um pico enorme, que encobria o Sol. Porém, com o passar dos anos o pico foi sendo consumido pela Vale, até se tornar uma mina esgotada. O engenheiro Júlio Cézar Moreira relata algumas mudanças na paisagem da cidade:

"Eu não sei se vocês conhecem bem Itabira, mas, se
for nessa direção do Pontal, vocês vão ver a quan-
tidade de fino. A gente ia para Santa Maria, eu era,
bastante tempo atrás, menino, passava uma ponte e
tinha um córrego lá embaixo. Hoje, a ponte sumiu.
Muito lugar aqui que a gente circulava aí, a gente via
poste que tinha umas casinhas, uma casa lá que a Vale
desapropriou, o poste ia sendo assoreado e já sumiu
também o poste. Essa parte do Pontal é muito fina, 
demais... é... o melhor para ver é as imagens de satélites atuais. Vai pegando até quando teve as primeiras imagens de satélites do Google e pode comparar também para você ver o impacto, como mudou em termo de vegetação nativa" (Moreira, 2015).

A mudança na paisagem não se limitou ao aspecto natural, mas também à infraestrutura urbana, principalmente com a destruição de vários bairros. Talvez o caso mais emblemático seja da Vila Paciência, localizada nas proximidades da mina do Chacrinha. Essa mina pertencia originalmente à Acesita; como era um ativo secundário, de baixa exploração, não impactou consideravelmente a cidade. Com a compra pela Vale, nos anos 1990, houve uma intensificação das operações e expansão da mina em direção à cidade, até uma distância inferior a 50 metros.

Com isso, acentuaram-se os problemas sentidos pelos moradores de Vila Paciência. Entre esses, os mais comuns são, além do material particulado, o ruído e a vibração que, de acordo com relatos, levam ao surgimento de rachaduras, ruptura de vidros e danificação dos imóveis. Como consequência, houve uma desvalorização significativa dos imóveis.

Para resolver o impasse, iniciou-se o processo de compra dos imóveis pela Vale. Porém, muitos moradores questionaram os valores oferecidos pela mineradora, optando por estender a negociação, na tentativa de conseguir propostas mais justas. Além disso, o esvaziamento do bairro levou à redução dos serviços públicos, como transporte e segurança. Assim, uma nova frente de disputa surgiu para os moradores, dessa vez contra a Prefeitura, de forma a garantir a qualidade de vida no bairro (Souza, 2007).
Assim, surgiu em Vila Paciência um misto de indignação e revolta. Ao mesmo tempo, os moradores sentiam-se expostos a diferentes riscos, principalmente de acidentes. Conforme narrado por Souza (2007), houve, por exemplo, o caso de descarrilamento de três vagões de minério, que caíram sobre a rua, chegando mesmo a romper a rede de abastecimento de água.

\begin{abstract}
"É...a Vila Paciência, eles chamam Vila Paciência de Cima e Vila Paciência de Baixo. A 'de Cima', na década de [19]80, eles tiraram, aí tiveram que passar esse... esse aqui era da Vale, essa área aqui passou e outro parque, Mata do Bispo, foi passado para o município como se fosse troca pela infraestrutura urbana que tinha lá, arruamento, pavimentação, rede de distribuição de água e esgoto. Depois, por exigência dessa licença ambiental de 2000, exigiu que fizesse estudo, porque tinha muita reclamação da Vila Paciência de rachadura de casa em função da mineração e exigiu que se fizessem os estudos, foram feitos alguns estudos, e que fizesse um acordo. No final das contas, ela optou por comprar umas casas. [...] Então, até hoje, tem desapropriação lá. É um bairro que ficou meio fantasma, impacto da mineração também" (Moreira, 2015).
\end{abstract}

Como resultado, surgiu um forte movimento contra a expansão da Vale no bairro. Entretanto, sua efetividade tem se mostrado limitada - principalmente devido ao seu isolamento. Os moradores de Vila Paciência, de forma geral, não conseguiram obter apoio dos órgãos públicos municipais, nem da população em geral. Depois da oferta da compra dos imóveis pela empresa, eles deixaram de receber solidariedade da população (Souza, 2007). 


\subsection{Poluição atmosférica}

Se a mudança urbana atingia apenas alguns grupos, a questão da poluição atmosférica foi um dos impactos que mais marcaram a população de Itabira. Essa poluição está, principalmente, associada com a emissão de material particulado, gerado com o desmonte mecânico do minério e do solo. Como consequência, Itabira apresenta, em determinados períodos, um cenário coberto de nuvens de poeira avermelhadas. O relevo do município, cercado por colinas, dificulta a dispersão do material particulado, agravando a situação (Braga et al., 2007).

Diante dos problemas relacionados à poluição atmosférica, a Vale adotou uma série de iniciativas de controle ambiental, porém, sem o resultado desejado. Entre as iniciativas para redução da emissão de material particulado, foram implantados diferentes sistemas, como umidificação das estradas de acesso às minas, bem como aspersão de polímeros sobre vagões e taludes. Todavia, dada a posição das minas e proximidade da área urbana, os efeitos de tais iniciativas não se mostraram efetivos e a emissão de material particulado continuou afetando negativamente a cidade (Souza, 2007).

A emissão de material particulado tem impactos estéticos e sanitários. No caso específico de Itabira, existe a percepção de que a baixa qualidade do ar aumenta o número de casos de doenças respiratórias, em especial, em crianças e adolescentes, e doenças cardiovasculares em idosos.

Em decorrência dessa situação, Santi et al. (2000) realizaram um levantamento da qualidade do ar para o período entre 1997 e 1999. A pesquisa mostrou repetidas violações dos limites definidos pela Resolução CONAMA 03/1990, especialmente nos bairros próximos à mina. Em outro estudo, Braga et al. (2007) concluíram que a poluição do ar em Itabira se equiparava à dos grandes centros urbanos. Estes autores buscaram analisar o impacto dessa poluição sobre a saúde das pessoas e identificaram que o aumento de $10 \mu \mathrm{g} / \mathrm{m}^{3}$ de material particulado no ar, aumentaria em $4 \%$ o número de atendimentos de crianças e adolescentes por doenças respiratórias.

Pesquisas mais recentes de mesma natureza não foram identificadas na literatura. Entretanto, dados preliminares sugerem melhora transitória na qualidade do ar na cidade. Conforme apresentado na Figura 1, houve uma tendência na redução na taxa de internação por doenças do aparelho respiratório no período 1998-2004; todavia, essa diminuição foi interrompida a partir de 2005, quando se percebe um aumento significativo nas internações.

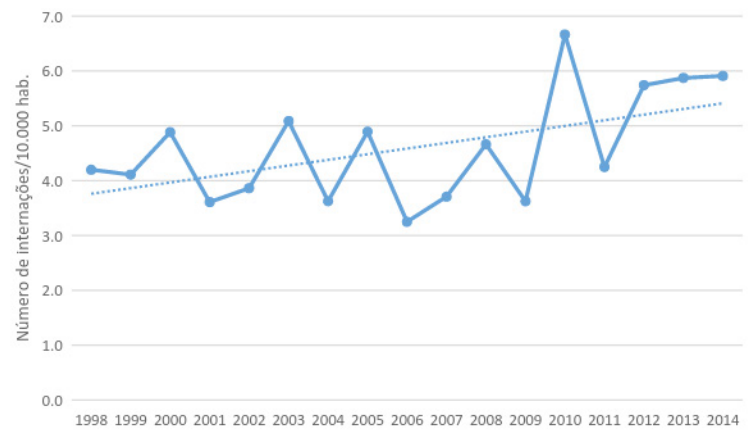

FIGURA 1 - Internações por doença do aparelho respiratório. FONTE: Adaptado de DATASUS (2016);

\subsection{Suicídios}

Os impactos da atividade mineradora na saúde da população de Itabira não se limitam a questões físicas, estando também fortemente associados ao 
sofrimento mental. Nesse sentido, a ocorrência de doenças mentais, em particular depressão, passou a chamar a atenção de Itabira a partir da publicação do estudo de Souza et al. (2007), que identificou que, para o período entre 1990 e 2001, a taxa de suicídio no município não apenas era mais elevada que a média da população brasileira, como ainda apresentava tendência de crescimento. O estudo indicou ainda que, dentre os casos de suicídios no município, notava-se um número elevado de pessoas casadas, o que seria uma anomalia, uma vez que dados internacionais indicam que os suicídios geralmente ocorrem com maior frequência entre pessoas solteiras. Ao mesmo tempo, outra faixa que apresentava elevados índices de suicídios era a de pessoas com baixo grau de escolaridade.

Diante de tais evidências, as autoras conjecturaram que a situação econômica do município teria uma relação com a elevada taxa de suicídios. Segundo elas, o período estudado coincidiria com as mudanças ocorridas na indústria de extração de minério de ferro e com a transição da Vale, de uma empresa pública para uma privada. Esse processo teria sido marcado pela constante ameaça de redução nos salários e demissões, gerando grande apreensão entre os trabalhadores. Num contexto geral, o aumento da taxa de suicídio se tornaria considerável em tempos de instabilidade histórica e mudanças sociais, diferentemente de períodos de estabilidade, em que o número de casos se mostraria constante. Este estudo teve relevância para a percepção local sobre suicídios que, quase dez anos depois, continua sendo uma preocupação da população.

“Como você percebe, essa questão do suicídio, e indo além disso, né, é um problema. Suicídio é uma questão que tá ligada à depressão, a determinadas condições psicológicas, isso conecta com alcoolismo, com drogas, que é muito comum em trabalhadores mineiros. Itabira tem esse problema do suicídio, que é muito sério, e quem será em comum que pode explicar e vai passar por vários e vários e vários e vários pontos de discussão. E Itabira é uma cidade tão pobre, uma cidade operária, alto índice de alcoolismo, só tem boteco e o álcool é supressor emocional, sabe disso. Lazer, cultura, quase nenhum. Deu uma melhoradinha agora, nesse governo aqui, passou um bom tempo sem ter atividade cultural dentro de Itabira que prestasse, né, então..." (Gonzaga, 2015).

Da mesma forma, dados recentes indicam a necessidade da atualização de pesquisas sobre suicídio no município. Em primeiro lugar, a Figura 2 mostra como a taxa de suicídios em Itabira é superior à taxa de Belo Horizonte. Em segundo lugar, mostra um comportamento bastante particular. A taxa de suicídios teve uma redução significativa entre os anos 2000 e 2009, que coincidem quase integralmente com o período do boom da demanda internacional por minério de ferro (2003-2011). A partir de 2009, quando o comportamento do mercado começou a se alterar, essa taxa aumentou, atingindo patamares superiores àqueles identificados no período da privatização da empresa.

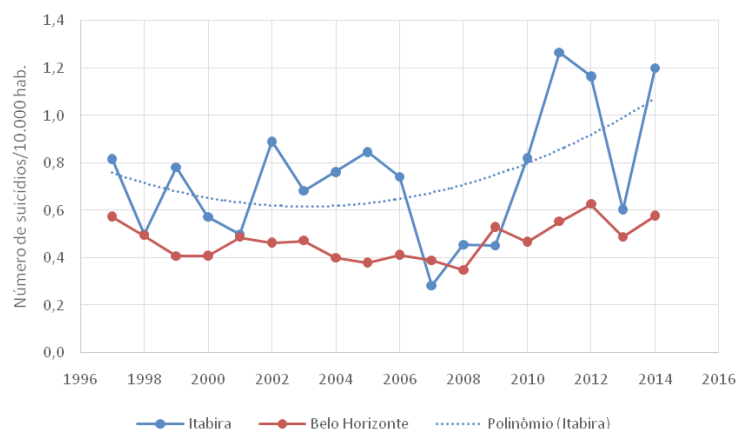

FIGURA 2 - Taxa de suícidios

FONTE: Adaptado de DATASUS (2016); 


\section{A reação de Itabira e suas limitações}

\subsection{Movimentos sociais}

Apesar de haver certo grau de mobilização social em Itabira, ainda não foi identificado um processo consistente de contestação social com relação à presença da Vale. Seja por características da sociedade Itabirana, seja pela forma como a companhia se instalou, o que se percebe é um movimento social acrítico, que pouco se mobiliza para questionar os impactos da mineração sobre a cidade.

Uma das instituições pioneiras na cidade foi a Associação Comercial, Industrial, de Serviços e Agropecuária de Itabira (ACITA), criada em 1925. Voltada principalmente para atender interesses do empresariado local, a ACITA atuava em duas linhas: prestar serviços aos seus membros e solidificar condições para promover negócios em parceria com outras instituições e o poder público (Presas, 2012).

Outra organização muito importante no contexto social da cidade, é a Interassociação de Bairros. Criada em 1973, por integrantes das diferentes associações de moradores, a "Inter" (como a organização é chamada em Itabira) tem como principal finalidade unir os interesses dessas associações. Sua atuação histórica foi, principalmente, participar de conselhos municipais, tendo uma postura muito próxima ao poder público municipal, sem ter uma atuação crítica muito forte (Presas, 2012).

A partir da segunda metade dos anos 1980, surgiu uma grande quantidade de organizações. Tal processo poderia ser associado à distensão do regime militar e à redemocratização do país. Nesse período, foram criadas, por exemplo, a Associação dos Deficientes Ocupacionais e Físicos de Itabira; a Associação de Aposentados; Associação de Cidadãos Seniores e o Movimento dos Estudantes da FUNCESI (Tubino et al., 2011).

Um dos aspectos importantes desse processo, é a falta de crítica à Vale. Apesar dos diferentes impactos mencionados na seção anterior, poucas organizações se propõem a contestar a empresa e suas práticas. Nesse sentido, durante a pesquisa de campo, Souza (2007, p. 73) identificou que haveria uma "poluição da mente do itabirano", "porque todo mundo ainda quer trabalhar, prestar serviço e vender para ela [Vale]".

Mesmo o movimento ambientalista da cidade surgiu com baixa perspectiva crítica. Seu principal marco foi o "Encontro Nacional dos Municípios Mineradores" - realizado em 1984. O encontro envolveu não apenas a população desses municípios, mas também representantes dos governos municipais e das empresas mineradoras. Um dos principais exemplos desse processo foi a Sociedade Ambiente Vivo de Itabira (SAVI), cujo objetivo fundamental era a promoção de projetos de educação ambiental. Apesar de obter recursos a partir dos Termos de Ajuste e Conduta (TACs), não é incomum que a SAVI busque ainda oportunidades de parceria com a Vale (Presas, 2012).

\subsection{Ações de controle ambiental}

Assim como no caso da mobilização social, também a organização do governo municipal para lidar com os impactos da mineração foi tardia e pouco eficaz. De acordo com Silva (2004, p. 225), "a questão ambiental em Itabira tomou proporções alarmantes pela degradação da paisagem, poluição 
de toda ordem, decorrente do modelo de desenvolvimento baseado na atividade extrativa mineral por mais de cinquenta anos". A atuação dos agentes do Estado, porém, não pareceu se mostrar à altura dos problemas.

A primeira intervenção mais efetiva do Estado sobre os impactos ambientais da mineração ocorreu em 1982, na forma de uma Ação Civil Pública (ACP) em função do problema de poluição do ar (Tubino et al., 2011). Apesar da criação do Conselho Municipal de Defesa do Meio Ambiente (CODEMA), em 1984, este atuou pouco no sentido de restringir os impactos da atividade mineral. Novas iniciativas somente se dariam em 1992, quando a Vale foi objeto de outra ACP - também relativa a problemas ambientais (Tubino et al., 2011; Presas, 2012).

Ações concretas, entretanto, demoraram para ser realizadas. Apenas em 1994, oito anos após a aprovação da Resolução CONAMA 01/1986, o Governo do Estado convocou a Vale a obter uma Licença Operacional Corretiva (LOC). Essa exigência foi coincidente com o anúncio feito pela Vale, de que iria encerrar suas atividades em 2025. Essa decisão teve forte impacto sobre a população, que passou a demonstrar publicamente, de forma crescente, descontentamento com a atuação da empresa. Como forma de amenizar a situação, em 1996, o Executivo municipal propôs uma ação indenizatória contra a empresa e a União (Presas, 2012). O descontentamento da população com a Vale foi se aprofundando à medida que a empresa passava pelo processo de adequação e, posterior, privatização. Durante esse período, conforme mencionado anteriormente, houve um intenso processo de demissão e de redução de benefícios.

A formulação da LOC durou vários anos. Um dos seus marcos, foi a audiência pública de 12 de fevereiro de 1998, que contou com a participação de mais de 800 pessoas. Esse foi um dos primeiros momentos em que a população criticou abertamente a empresa. Apesar da mobilização, a influência da Vale ainda se manteve bastante forte, mesmo depois da privatização. Após a audiência pública, a Fundação Estadual do Meio Ambiente (FEAM) e o CODEMA ainda negociaram com a empresa por dois anos, até chegarem a um acordo sobre as ações compensatórias a serem implementadas. A LOC foi assinada somente em 5 de junho de $2000 \mathrm{e}$ abrangeu 52 condicionantes. Todavia, algumas condicionantes relativas à degradação ambiental não foram cumpridas conforme estipulado, o que levou a empresa a pedir extensão de algumas delas - como aquelas relativas ao aterro sanitário, à qualidade das fontes de água, à compensação de biodiversidade e ao desmatamento (Tubino et al., 2011).

"Uma administração que começou no ano [19]96 a 2000, não se tinha licença, a Vale operava aqui sem licença ambiental. [...]. É... foi convocada a audiência pública, que é um marco. [...]. É porque a Vale tinha entrado com o processo de licenciamento no ano $2000 . . .[\ldots]$. Foi considerada a maior a licença ambiental do Brasil, quando ela saiu, saiu no ano de 2000, foram dois anos de discussão, foi fevereiro de 1998 que foi a audiência pública, e culminou em junho de 2000, que foi que a Vale obteve a licença, 52 condicionantes, evidentemente, com prazo para cumprir. Porém, é questão de política municipal, mudou-se a política no ano 2000. A administração, que, vamos dizer assim, exigiu o licenciamento da Vale, perdeu a política e os outros governantes, é... é claro que é conivência da Vale, muitas dessas condicionantes não foram cumpridas por acordo. [...] Essas condicionantes, elas não foram cumpridas, grande parte delas, eles alegam que foi [...]" (Moreira, 2015). 
Os principais problemas sentidos pela sociedade, que levaram a população a se mobilizar diante da negociação da LOC pela Vale, permaneceram polêmicos na cidade por vários anos.

"É, só que posso dizer que todos eles foram arquivados por cumprimentos ou foram iniciadas ações. Hoje, em relação às condicionantes, eu tenho um inquérito residual. [...]. Tem uma das condicionantes, deixa eu lembrar o nome, o número, mas ela determinava que a Vale ficaria responsável por fazer um estudo a respeito de um novo local de captação de água no município, que é um problema nosso aqui. É... e aí cria a divergência de atendimento, a Vale, entendo que ela cumpriu, porque ela entendia que a obrigação era fazer o estudo, e a prefeitura, entendo que não, entendendo que ela teria que executar esse projeto, né, esse estudo. Então, a gente está nesse impasse. O órgão ambiental, no entanto, ele entendeu como cumprida" (Fonoff, 2015).

Assim, passados 15 anos do estabelecimento da LOC, sua implementação manteve-se como ponto de divergência entre a empresa e os grupos da sociedade. Em entrevistas, realizadas em 2015, apesar de alguns entrevistados afirmarem que todas as condicionantes tinham sido cumpridas, haviam aqueles que indicavam que algumas tinham sido apenas parcialmente atendidas.

\section{Dependência econômica, riscos e tentativas de superação}

\subsection{A dependência econômica}

Nem sempre Itabira teve sua economia vol- tada para a mineração. Antes da exploração das jazidas de minério de ferro, desenvolviam-se no município outras atividades econômicas, como a fabricação de arreios, a agricultura, a pecuária e a confecção de tecidos de algodão. Com a expansão das atividades minerárias, houve transformações na cultura, na economia, no meio ambiente, e as outras atividades, aos poucos, foram perdendo espaço para a mineração (Presas, 2012).

O desenvolvimento de outras atividades foi, de certa forma, inibido pela atividade de mineração. Ao longo da história de Itabira, principalmente durante a fase da Vale Mãe, era difícil competir com os benefícios que a Vale proporcionava aos seus trabalhadores. Assim, quando apareciam outras empresas, elas não conseguiam se manter, devido à forte concorrência da Vale pela mão de obra. As duas empresas têxteis que se instalaram no início do século XX (Fábrica Gabiroba e Fábrica da Pedreira) são exemplos desse processo. Como elas não conseguiram manter mão de obra qualificada, não tiveram outra saída a não ser encerrar suas atividades, uma no final da década de 1960 e outra no início da década de 1970. Assim, as únicas empresas que conseguiram se fixar na cidade seriam as prestadoras de serviço da Vale, o que intensificava ainda mais dependência do setor mineral (Enríquez, 2007; Saraiva \& Carrieri, 2012). De acordo com Presas (2012), a população de Itabira, desde a criação da Vale, viveu presa à mineradora, aos seus benefícios, ao seu poder e influência, negligenciando outras atividades. A partir dos anos 2010, a empresa e suas terceirizadas ainda eram a base da economia do município (Tubino et al., 2011).

[...] as pessoas [...] foram criadas com o nível de dependência de dominação tão grande. Diz não mexer 
com a Vale não... meu filho um dia pode tralhar lá [...] Não vou mexer não, porque meu irmão trabalha lá. Não vou mexer porque meu tio trabalha. Sabe essas coisas, né? Tá tudo circulando em volta dela, em torno. Ela é dominadera mesmo, né? Por isso, a cidade não grita (Gonzaga, 2015).

A dependência da cidade em relação à mineração se manifesta não apenas em termos de emprego, como também do próprio orçamento da administração pública. As contribuições da atividade mineral são as principais fontes de recurso da Prefeitura Municipal de Itabira. Muito do que se discute em termos de orçamento público relaciona-se à Compensação Financeira pela Exploração de Recursos Minerais (CFEM). Além dela, porém, a receita municipal também se beneficia do Imposto sobre Serviços (ISSQN), do acréscimo do Valor Adicionado Fiscal (VAF) e de parcela do Imposto sobre Circulação de Mercadorias e Prestação de Serviços (ICMS) - (Enríquez, 2007; Presas, 2012; Saraiva \& Carrieri, 2012).

"E a cidade [...] é refém economicamente até hoje, refém da Vale. Hoje, a Prefeitura, né, em termo de imposto, a renda do município é exclusivamente... não é exclusivamente, mas gira em torno dos royalties e dos impostos pagos pela Vale." (Membro da Organização Acaó, 2015)

Uma economia baseada em recursos minerais, porém, precisa lidar com diferentes particularidades deste setor. No caso de Itabira, duas que se mostram muito relevantes são a volatilidade do preço dos minérios e a sua finitude.

\subsection{A volatilidade do preço do minério e os impactos sobre Itabira}

O setor mineral caracteriza-se por um descompasso cíclico entre oferta e demanda. Devido à escala de operação, aumentos de produção ocorrem apenas em determinados momentos - e em grandes saltos. Essa dinâmica cria desequilíbrios periódicos na relação entre oferta e demanda, causando grande variação nos preços.

Embora o crescimento da Vale tenha ocorrido sem grandes percalços, até a década de 1980, esse ciclo foi interrompido devido à drástica redução do preço do minério de ferro no mercado mundial naquele momento. Esse processo esteve associado à crise do petróleo, ainda em 1973, e à recessão econômica dos EUA, que levou à diminuição do consumo de commodities ${ }^{3}$. Assim, apesar de haver minérios disponíveis, considerando os baixos preços da época, sua extração deixava de ser economicamente viável, o que colocou - pela primeira vez - em risco a economia da Itabira.

O período de instabilidade se manteve durante a década de 1990, e somente foi superado no início dos anos 2000, devido à demanda crescente de minérios pela China, acompanhada de um crescimento sem precedentes no preço do minério de ferro. A demanda da China por minério parecia inesgotável e o novo patamar de preços permitiu que a Vale continuasse explorando as antigas minas de Itabira, mesmo que o minério de qualidade não fosse tão abundante e os custos operacionais fossem mais elevados do que, por exemplo, no Complexo Carajás (Presas, 2012).

\footnotetext{
${ }^{3}$ A expressão commodities é comumente utilizado para definir bens básicos uniformes produzidos por diferentes empresas ou países e que são comercializados sem beneficiamento. Este termo ser refere, principalmente, a produtos agrícolas, metais e combustíveis.
} 
Esse cenário, entretanto, foi novamente modificado com a crise financeira de 2008, quando uma queda momentânea no preço do minério de ferro trouxe de volta a ideia de desemprego e a ausência dos royalties ${ }^{4}$ pairou sobre a cidade. Por exemplo, naquele ano, o município, que arrecadava da CFEM R \$ 49,6 milhões, somente obteve R \$ 33,2 milhões. Assim, a Prefeitura precisou trabalhar com a possibilidade de redução de $70 \%$ da arrecadação diante dessa situação. Além disso, a Vale demitiu um número significativo de pessoas e anunciou que esperava diminuir substancialmente seu faturamento (Saraiva \& Carrieri, 2012).

A partir de 2009, houve uma retomada dos preços, a crise foi percebida como uma "marola" e novos projetos foram retomados. Porém, o fim do "boom" das commodities, a partir de 2011, comprovou que a dependência da mineração expunha a cidade de Itabira a grandes riscos. Dessa vez, o impacto se deu de forma estrutural, atingindo arrecadação municipal, emprego e dinâmica econômica. Por exemplo, entre 2013 e 2014, a arrecadação da CFEM passou de R\$ 125 milhões para R\$ 60 milhões (Tesouro Nacional, 2016). Ao mesmo tempo, houve uma redução no número de postos de trabalho, conforme apresentado na Figura 3.

Essa redução no orçamento municipal e no número de pessoas contratadas teve impactos diretos na economia do município.

"Pra você ter ideia, [...] estava US\$ 180 a tonelada, baixou pra US\$ 62 a tonelada. Então, assim, isso vai impactar diretamente todas as cidades mineradoras. É por isso essa preocupação da diversificação (Silva, S. 2015).

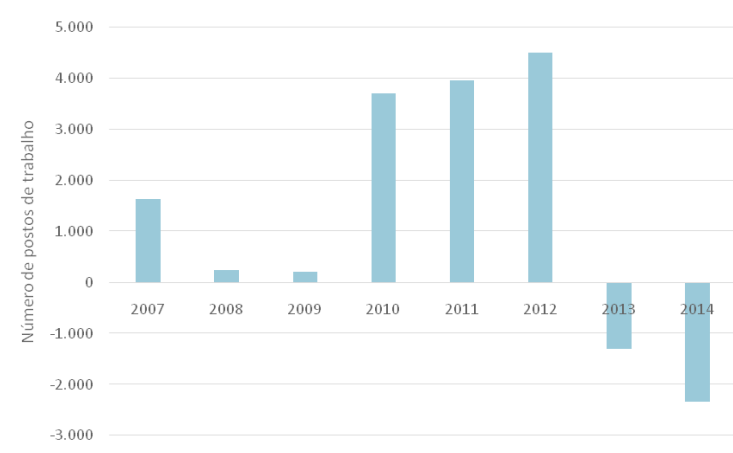

FIGURA 3 - Variação no número de postos de trabalho em Itabira (admissões menos demissões)

FONTE: Ministério do Trabalho e Emprego (2016).

Por um lado, a Prefeitura teve de gastar menos; por outro, o aumento do desemprego reduziu consideravelmente as vendas do comércio e o aluguel de imóveis, levando a crise para outros setores da economia do município (Rodrigues, 2015). Em momentos de crise, tornam-se mais explícitos para a sociedade de Itabira os riscos associados à sua dependência econômica na relação com a mineração e com a Vale. Dessa forma, houveram diferentes tentativas de promover a diversificação econômica do município, porém ainda sem o devido sucesso.

\subsection{Para além do minério: entre a diversificação econômica e o aprofundamento da dependência}

Um segundo desafio econômico, colocado para Itabira, diz respeito à finitude das reservas de minério de ferro. Recursos minerais, por definição, são não-renováveis e têm um horizonte de aproveitamento (Lopes \& Ruckys, 2015). Quando comunidades, como Itabira, apostam no crescimen-

\footnotetext{
${ }^{4}$ A Constituição Federal, em seu artigo 20, define que os recursos minerais são bens da União. Assim, empresas que exploram minérios são obrigadas a pagar royalties a título de compensação pela extração de tais recursos.
} 
to econômico baseado em tais recursos, elas devem considerar que, eventualmente, esses recursos irão se esgotar e elas entrarão em um processo de recessão econômica.

Apesar desse fato, Itabira vem levando um longo período para se preparar para esse momento. De forma geral, ao longo de sua história, a cidade tem vivido um permanente dilema entre apostar na diversificação econômica ou aumentar sua dependência da mineração. Aparentemente, ela tem repetidas vezes optado pela segunda alternativa, apostando no aumento da cava ou nos avanços tecnológicos.

A entrada da Vale, nos anos 1940, foi baseada na extração de hematita, considerada como minério de melhor qualidade por poder conter até $70 \%$ de ferro. As reservas começaram a se esgotar nos anos 1960, quando a Vale inaugurou o Centro de Desenvolvimento Mineral, em busca de um processo para explorar itabirito friável. Tecnologias desenvolvidas, a partir de 1973, permitiram a extração de itabirito, considerado inferior por apresentar até $50 \%$ de teor de ferro. Este começou a ser explorado com a construção de uma usina de concentração na mina Cauê, com o objetivo de sinterização e pelotização do minério (CVRD, 2002 apud Presas, 2012).

Dilema semelhante se deu no início dos anos 1990. Nesse momento, foi anunciado que as reservas de Itabira somente iriam durar mais 35 anos. Assim, foi criado o projeto Itabira 2025 - com a participação da ACITA, sindicatos, organizações sociais, Prefeitura, dentre outros, que buscavam alternativas econômicas para a cidade quando a Vale encerrasse suas atividades.

Junto com o Itabira 2025, criou-se também a Agência de Desenvolvimento de Itabira (ADI), com o objetivo de fortalecer experiências de gestão em conjunto com empresas e instituições para o desenvolvimento municipal. A ADI foi criada com o auxílio do Instituto de Desenvolvimento Industrial de Minas Gerais (INDI); e em parceria com o Serviço Brasileiro de Apoio às Micro e Pequenas Empresas (SEBRAE) e o Banco de Desenvolvimento de Minas Gerais (BDMG).

Uma das principais iniciativas do ADI foi a criação do Fundo de Desenvolvimento Econômico de Itabira (FUNDESI), que buscava criar condições financeiras para incentivar a diversidade econômica. Esse fundo contaria com recursos da CFEM, e seria supervisionado pelo Conselho Municipal de Desenvolvimento Econômico de Itabira (CODECON) - formado por membros da ACITA, do Sindicato de Trabalhadores de Itabira, da Associação dos Aposentados da Vale (APOSVALE), da Inter-Associação de Moradores de Itabira, do CODEMA e da própria Vale, além de representantes da Prefeitura e da Câmara de Vereadores (Presas, 2012).

De acordo com Enríquez (2007), a proposta do FUNDESI colocou Itabira como um dos pioneiros entre os municípios mineradores a discutir a diversificação econômica. Segundo a autora, Itabira se destacaria por possuir uma legislação própria sobre o uso da CFEM e também por utilizar este recurso para um plano de desenvolvimento produtivo. A proposta, porém, apresentou diferentes limitações. Presas (2012) alerta que os recursos não foram aplicados corretamente, impedindo a criação de soluções para diversificar a economia de forma a que a cidade continuasse a se desenvolver mesmo sem a mineração.

As primeiras tentativas de uso do FUNDESI, foram destinadas a empréstimos para ativos fixos e projetos de infraestrutura relacionados com 
as atividades industriais e agroindustriais. Logo no início, entre 1993 e 1996, um total de 76 empréstimos foram concedidos às empresas instaladas em distritos industriais de Itabira. Porém, a utilização desses recursos enfrentou uma série de dificuldades, como falta de administração dos fundos pelo governo, que não cobrava com rigor as obrigações dos credores e o dever com as cláusulas contratuais. Além disso, foi identificada falta de continuidade política, uma vez que não havia garantias de que novos prefeitos mantivessem projetos iniciados por seus antecessores. Como consequência desse cenário, os resultados ficaram aquém do esperado. Empresas se instalaram em terrenos doados pela Prefeitura, porém elas não se viabilizaram economicamente, o que logo levou ao esvaziamento do Distrito Industrial I (Enríquez, 2007; Presas, 2012). Sobre esse assunto, Oliveira (2015) confirmou que os resultados desse distrito não foram os esperados e que ainda haviam áreas onde as empresas não deram certo e acabaram decretando falência.

Ao mesmo tempo que a cidade buscava alternativas à mineração, ela continuava apostando na sua expansão. Também, no início dos anos 1990, foi colocada em discussão a expansão da mina do Chacrinha, muito criticada pela sua proximidade com a área urbana da cidade. Embora grupos apontassem os impactos ambientais negativos de tal decisão, a não-exploração da mina do Chacrinha foi interpretada como uma grande perda econômica (Silva, 2004). Por fim, foi decidida a expansão da mina, gerando uma série de conflitos com moradores da cidade, particularmente no bairro da Vila Paciência (Souza, 2007).

No início dos anos 2000, ao mesmo tempo que o FUNDESI apresentava resultados decepcionantes, aumentava a demanda chinesa por minério de ferro e se iniciava um novo ciclo de alta de preços. Com isso, não apenas os empreendimentos de diversificação arrefeceram, como ainda houve uma nova onda de investimentos em projetos de mineração. Assim, a Vale anunciou que iniciaria estudos para aproveitamento do itabirito compacto, uma forma de minério mais duro e com maior teor de sílica. O desenvolvimento de tal tecnologia permitiria, então, a manutenção da mineração na cidade (Santos \& Milanez, 2015; Saraiva, 2012). A implantação do Projeto Itabiritos foi iniciada nos anos 2010, e a nova planta de beneficiamento em Itabira entrou em operação em 2015 - ampliando a vida útil do Complexo Itabira em mais 20 anos (Durão, 2015).

Todavia, o fim do "boom" das commodities levou a população a debater novamente possíveis alternativas à mineração. Dentre as possíveis vocações locais, houve quem apontasse para a cidade como um potencial polo regional de educação e saúde, a partir da estrutura construída inicialmente para atender aos funcionários da Vale.

Do ponto de vista da saúde, a cidade conta com 380 estabelecimentos e é referência na sua microrregião (Presas, 2012). A consolidação da área está associada, novamente, com a dependência da Vale. Nesse sentido, "A Vale tem sido uma importante parceira, porque ela tem feito alguns convênios que estão contribuindo para a construção de prédios e equipagem dos hospitais [...] para que estes possam prestar o melhor serviço, então a Vale contribui" (Oliveira, 2015).

No campo da educação, a cidade tem apostado, principalmente, no investimento em ensino superior, por meio da inauguração de um campus avançado da Universidade Federal de Itajubá (UNIFEI). A proposta da UNIFEI, por um lado, caminhava no 
sentido de fortalecer a educação na cidade e, ao mesmo tempo, seria um atrativo para novos negócios. As atividades do campus da UNIFEI tiveram início em 2008, e suas instalações foram construídas em terreno cedido pela Prefeitura, sendo a Vale responsável pela aquisição dos equipamentos dos laboratórios. A universidade passou a oferecer, inicialmente, dez cursos de engenharia. Esse foco nas áreas tecnológicas e ênfase na formação de mão de obra para atividades de mineração, entretanto, foi questionado por alguns atores, uma vez que manteria também essa instituição fortemente ligada à Vale, além de oferecer poucas oportunidades de formação para atuação em outros setores econômi$\cos$ (Presas, 2012).

$\mathrm{Na}$ área da educação também, que a gente entende que Itabira, ela pode ter aí a sua diversificação em razão da educação. É a implantação aqui da Universidade Federal de Itajubá, que é a UNIFEI.[...] Então, nós temos aí a saúde, a educação, né?, que estão, tendo aí um grande impulso na cidade, que contribui para a diversificação econômica e com o apoio da Vale “ (Oliveira, 2015).

Ainda um terceiro caminho, proposto para diversificar economia de Itabira, se baseia em um projeto da Secretaria de Desenvolvimento Econômico do município, também em parceria com a Vale. A proposta é construir um novo distrito industrial.

"Nós devemos lançar agora, em abril ou maio, o novo Distrito Industrial, que também é trabalho dessa secretaria, onde a Vale tá sendo parceira na doação de 300 ha de área... é um terreno de 300 ha.. Poderá ser um dos cinco maiores distritos industriais de Minas Gerais e, além dela doar essa área sem nenhum ônus para o município, é uma forma dela contribuir" (Oliveira, 2015).
O projeto também espera atrair novas empresas, motivadas pelas vantagens concedidas pela Prefeitura, mas, diante do fracasso que foi o projeto com recursos do FUNDESI para atrair novas empresas para o Distrito Industrial I, torna-se questionável a insistência na ideia.

Então hoje, nós temos com parceria junto a FIEMG, nós temos hoje um consultor da FIEMG que mora em Milão, que está buscando lá empresas que se interessassem em vir pro Brasil, e ele está referendando Itabira como uma cidade preparada para receber investimento.[...] Nós temos aí toda uma estratégia de atração de empresas [...] os incentivos são aqueles antigos, muito comuns aí na maioria das cidades, que é a doação do terreno, que é a isenção de IPTU, ISS, que é o apoio através do SENAI, que é formação de mão de obra, que é o apoio da própria Prefeitura, redução das burocracias" (Oliveira, 2015).

Dessa forma, os resultados da busca pela diversificação econômica ainda são incertos. Diferentes propostas produziram resultados sempre aquém do planejado, o que coloca em dúvida a capacidade do município de efetivamente promover a diversificação de suas atividades e tornar-se independente da extração mineral.

\section{Conclusões}

A literatura sobre mineração vem sendo construída de forma polarizada em diferentes campos, entre eles: impactos socioambientais, relações com a comunidade e crescimento econômico. A partir dessa tipologia, buscou-se identificar alguns elementos críticos na relação construída entre a Vale S.A. e a comunidade de Itabira.

A presente análise sugere a necessidade 
da sociedade itabirana rediscutir o seu processo de desenvolvimento, seja devido às condições socioambientais às quais está exposta, seja pelas possibilidades de futuro que necessitam ser criadas.

Do ponto de vista meramente econômico, a mineração apresenta dois grandes inconvenientes: os recursos minerais são finitos, ou seja, tendem a se esgotar com o tempo; e o mercado internacional das commodities minerais é sujeito a grandes oscilações de preços, o que impacta fortemente as economias dependentes desse setor. Para o meio ambiente, os impactos, especialmente no caso do minério de ferro, são severos, como atesta a destruição do pico do Cauê. Além dos efeitos sobre as áreas de mananciais, levando à recente escassez de água no município. Da mesma forma, os riscos socioambientais das atividades minerais precisam ser recalculados, a partir da avaliação das consequências do rompimento da barragem do Fundão da mineradora Samarco (joint veture da Vale S.A. com a BHP Billiton), em Mariana (cf. Milanez \& Losekann, 2016). Ainda, impactos sobre a saúde da população precisam ser melhor estudados, seja pela poluição atmosférica, seja pela própria insegurança social decorrente da dependência econômica.

O desafio na busca da diversificação econômica vai além de definir quais as atividades mais adequadas. Já houve experiências anteriores baseadas na estratégia da criação de distritos industriais, mas sem resultados significativos. A economia brasileira vive um ciclo de desindustrialização nos últimos anos, com participação crescente de produtos primários na pauta de exportações e investimentos relativamente escassos na ampliação ou instalação de novos projetos industriais. Esse é um problema estrutural que deixa pouca margem aos municípios para o fomento à indústria. Ainda assim, um distri- to industrial é apresentado pelo poder público - e apoiado pela própria Vale - como solução.

Há o risco de que a iniciativa atraia projetos relacionados à atividade minerária, pouco contribuindo para romper a dependência econômica em relação à mineração, problema já identificado em experiências passadas. Outro inconveniente é a necessidade de renúncia fiscal como forma de incentivo para atrair empresas, o que reduziria significativamente a contribuição do distrito industrial na arrecadação de impostos e, consequentemente, para o incremento das receitas municipais e para a melhoria dos serviços públicos.

Por fim, a lógica dos distritos industriais insere-se em um modelo de urbanização que também impacta o meio ambiente, com riscos especialmente para as áreas de mananciais - já bastante afetadas pela atividade mineradora. Como o Vice-prefeito da cidade admitiu em entrevista, há limitações para a expansão no perímetro urbano de Itabira: "Olha, $60 \%$ do perímetro urbano dela, $60 \%$, ele é caracterizado por barragens de rejeito, áreas de preservação permanente e áreas de mineração. Então, ou seja, a cidade não tem como crescer nesse $60 \%$ do perímetro urbano, tá?"'(Oliveira, 2015). Por essa razão, a área escolhida para o novo distrito industrial fica fora do perímetro urbano, o que significa uma expansão de usos urbanos no território municipal, em contradição com uma perspectiva de recuperação do meio ambiente.

Por outro lado, as iniciativas nas áreas de saúde e educação apresentam vantagens relevantes. Contam com boa infraestrutura já existente, são atividades de reduzido impacto ambiental (desde que adequadamente implantadas), geram empregos qualificados e contribuem para a melhoria da qualidade de vida da população (ao ampliar o acesso a 
esses direitos básicos que são a saúde e educação). Faz-se necessária, porém, a ressalva ao fato de que o novo campus da UNIFEI oferece cursos relacionados à atividade minerária, em descompasso com a necessidade de independência em relação à mineração em geral, e à Vale, em particular.

O desafio posto, portanto, toma proporções significativas em Itabira, assim como em muitas outras cidades mineradoras. Os aspectos negativos da dependência econômica da mineração já vêm sendo profundamente trabalhados na literatura (Davis \& Tilton, 2005; Torvik, 2009). Porém, em muitos casos, procura-se definir o problema apenas como consequência da corrupção, da alta de visão estratégica ou da má governança (Humphreys et al. 2007, NGRI, 2015), e não como um elemento intrínseco à atividade extrativa.

O caso de Itabira, porém, sugere que há algo além. Existem questões econômicas inerentes ao setor extrativista que limitam consideravelmente o surgimento e consolidação de outros setores. Assim, entender em maior profundidade o caso de Itabira e de outras cidades do Quadrilátero Ferrífero, torna-se imperativo para debater a superação do modelo baseado em extração mineral na região.

\section{Agradecimentos}

Os autores gostariam de agradecer à Fundação de Apoio à Pesquisa do Estado de Minas Gerais (FAPEMIG) e ao Conselho Nacional de Desenvolvimento Científico e Tecnológico (CNPq) pelo apoio ao projeto de pesquisa que deu origem a esse artigo.

\section{Referências}

Auty, R. M. The political economy of resource-driven growth. European Economic Review, 45(4-6), 839-846, 2001.

Ballard, C.; Banks, G. Resource wars: the anthropology of mining. Annual Review of Anthropology, 32(1), 287-313, 2003.

Bastos, E. V. Itabira e a Companhia Vale do Rio Doce: interações e identidade no tempo da modernidade. Belo Horizonte, MG: PUC- MG, 2008. Originalmente apresentada como dissertação de mestrado ao Programa de Pós-Graduação em Ciências Sociais, Pontifícia Universidade Católica de Minas Gerais, 2008.

Bebbington, A.; B., Bury, J. (Orgs.). Subterranean struggles: new dynamics of mining, oil, and gas in Latin America. Austin: University of Texas Press, 2014.

Braga, A. L. F; Pereira, L. A. A.; Procópio, M.; André, P. A. de; Saldiva, P. H. do N. Associação entre poluição atmosférica e doenças respiratórias e cardiovasculares na cidade de Itabira, Minas Gerais, Brasil. Cadernos de Saúde Pública, 23(4), 570-578, 2007.

Caron, J.; Durand, S.; Asselin, H. Principles and criteria of sustainable development for the mineral exploration industry. Journal of Cleaner Production, 119, 215-222, 2016.

DATASUS. Informações de Saúde. Morbidade e informações epidemiológicas. Departamento de Informática do SUS. Disponível em: $<$ http://datasus.saude.gov.br/informacoes-de-saude/tabnet $>$. Acesso em: 01 jul.2016.

Davis, G. A.; Tilton, J. E. The resource curse. Natural Resources Forum, 29(3), 233-242, 2005.

Durão, M. Itabiritos amplia vida de minas da Vale. $O$ Estado de S. Paulo, São Paulo, 27 jul. 2015. Disponível em: $<$ http://economia.estadao.com.br/noticias/geral,nova-noticia,1732403\#cap1>. Acesso em: 04 jul. 2016.

ELAW. Guidebook for evaluating mining project EIAs. Eugene: Environmental Law Alliance Worldwide, 2010.

Enríquez, M. A. R. da S. Maldição ou Dádiva? Os dilemas do desenvolvimento sustentável a partir de uma base mineira. 2007. Tese de Doutorado - Centro de Desenvolvimento 
Sustentável, Universidade de Brasília, Brasília, 2007.

Faria, C. de O; Andrade, A. A. de. Itabira - MG. Enciclopédia dos Municípios Brasileiros. Edição de Jurandyr Pires Ferreira. Rio de Janeiro: Instituto Brasileiro de Geografia e Estatística, 1959. 25v.

Ferreira, C. R. de A. Carlos Roberto de Assis Ferreira: entrevista [mar. 2015]. Entrevistadores: B. Milanez, C. Guimarães, R. Santos e S. Castro. Itabira, 2015.

Fonoff, G. T. Giuliana Talomani Fonoff: entrevista [mar. 2015]. Entrevistadores: B. Milanez, C. Guimarães e R. Santos. Itabira, 2015.

Frochtengarten, F. Memória e Colonização em Carlos Drummond de Andrade. Psicologia \& Sociedade, 16(3), 97-101, 2004.

Gamu, J.; Le Billon, P.; Spiegel, S. Extractive industries and poverty: a review of recent findings and linkage mechanisms. The Extractive Industries and Society, 2(1), 162-176, 2015.

Gonzaga, C. E. Carlos Estevão Gonzaga: entrevista [mar. 2015]. Entrevistadores: B. Milanez, C. Guimarães, R. Santos e S. Castro. Itabira, 2015.

Gudynas, E. Extractivismos: ecología, economía y política de un modo de entender el desarrollo y na Naturaleza. Cochabamba: Centro de Documentación e Información Bolivia, 2015.

Humphreys, M.; Sachs, J. D.; Stiglitz, J. E. Escaping the resource curse, Nova York: Columbia University Press, 2007.

IBGE.Cidades@. Minas Gerais. Itabira. Disponível em: <http://cidades.ibge.gov.br/xtras/perfil.php?codmun=313170 . Acesso em: 01 jul. 2016.

Kirsch, S. Mining capitalism: the relationship between corporations and their critics. Oakland, California: University of California Press, 2014.

Laurence, D. Establishing a sustainable mining operation: an overview. Journal of Cleaner Production, 19(2-3), 278-284, 2011.

Lopes C.; Ruchkys. U. Recursos da geodiversidade de São Thomé das Letras - MG e seu uso para mineração e geoconservação: perspectivas para a reconversão desse território mineiro. Desenvolvimento e Meio Ambiente. 35, 335-347, 2015.

Membro da Organização Acaó. Membro da Organização Acaó: entrevista [mar. 2015]. Entrevistadores: B. Milanez e R. Santos.Itabira, 2015

Milanez, B.; Losekann, C. (Orgs.). Desastre no Vale do Rio Doce: antecedentes, impactos e ações sobre a destruição. Rio de Janeiro: Folio Digital; Letra e Imagem, 2016.

Ministério do Trabalho e Emprego. Perfil do Município. Disponível em: <http://bi.mte.gov.br/bgcaged/caged_perfil_municipio/index.php>. Acesso em: 04 jul. 2016.

Moreira, J. C. Júlio Cézar Moreira: entrevista [mar. 2015]. Entrevistadores: B. Milanez, C. Guimarães, R. Santos e S. Castro. Itabira, 2015.

NGRI. The resource curse: the political and economic challenges of natural resource wealth. NGRI Reader. Natural Resource Governance Institute, 2015

Oliveira, R. C. de. Reginaldo Calixto de Oliveira: entrevista [mar. 2015]. Entrevistadores: B. Milanez, C. Guimarães, R. Santos e S. Castro. Itabira, 2015.

Pantuza, F. M. G. Flávia Martins Guerra Pantuza: entrevista [mar. 2015]. Entrevistadores: B. Milanez, C. Guimarães e R. Santos. Itabira: FUNCESI-MG, 2015.

Power, T. M. Digging to development? a historical look at mining and economic development. [S.1.]: Oxfam America, 2002.

Presas, C. S. Instituições e Desenvolvimento em municípios de base mineira: os casos de Parauapebas - PA e Itabira MG. 2012. Dissertação de Mestrado - Centro de Desenvolvimento Sustentável, Universidade de Brasília, Brasília, 2012

Rajak, D. In good company: an anatomy of corporate social responsibility. Stanford, California: Stanford University Press, 2011. 318 p.

Rodrigues, A. Pedras no caminho de Itabira. Istoé, São Paulo, 06 jul. 2015. Disponível em: <http://istoe.com. br/425771_PEDRAS+NO+CAMINHO+DE+ITABIRA/>. Acesso em: 04 jul. 2016. 
Sagebien, J.; Lindsay, N. (Orgs.). Governance ecosystems: CSR in the Latin American mining sector. New York: Palgrave Macmillan, 2011.

Santi, A. M. M.; Suzuki, R. Y.; Oliveira, R. G. de. VI029 - Monitoramento da qualidade do ar no município de Itabira-MG: Avaliação dos Resultados em anos recentes (1997/99) e das perspectivas de modernização da rede de monitoramento no contexto do licenciamento ambiental corretivo da CVRD. In: XXVII Congresso Interamericano de Engenharia Sanitária E Ambiental, 2000, Porto Alegre. Anais... Porto Alegre: ABES - Associação Brasileira de Engenharia Sanitária eAmbiental, 2000. p. 1-12.

Santos, R. S. P.; Milanez, B. Redes Globais de Produção (RGPs) e conflito socioambiental: a Vale S.A. e o complexo minerário de Itabira. In: VII Simpósio Internacional de Geografia Agrária, 2015, Goiânia. Anais do VII Simpósio Internacional de Geografia Agrária, 2015. p. 2093-2108

Santos, R. S. P.; Milanez, B. The Global Production Network for iron ore: materiality, corporate strategies, and social contestation in Brazil. The Extractive Industries and Society, 2(4), 756-765, 2015.

Saraiva, L. A. S; Carrieri, A. de P. Organização-cidade: proposta de avanço conceitual a partir da análise de um caso. Revista de Administração Pública - RAP, 46(2), 547-576, 2012.

Silva, M. das G. S. e. A "Terceira Itabira": os espaços político, econômico, socioespacial e a questão ambiental. São Paulo: Editora Hucitec, 2004. 254 p.

Silva, R. S. da. Ronaldo Silvestre da Silva: entrevista [mar. 2015]. Entrevistadores: B. Milanez, C. Guimarães, R. Santos e S. Castro. Itabira, 2015.
Silva, S. J. da. Solimar José da Silva: entrevista [mar. 2015]. Entrevistadores: B. Milanez, C. Guimarães, R. Santos e S. Castro. Itabira, 2015.

Sinnott, E.; Nash, J.; Latorre, A. Natural resources in Latin America and the Caribbean: beyond booms and busts? Washington, D.C.: World Bank, 2010.

Souza, E. R. de; Minayo, M. C. de S.; Cavalcante, F. G. O impacto do suicídio sobre a morbimortalidade da população de Itabira. Ciência \& Saúde Coletiva, 11, 1333-1342, 2007.

Souza, M. R. G. A situação de vulnerabilidade da Vila Paciência de Baixo. Jornal Diário de Itabira, Itabira - MG, p. 04 - 05, 06 maio 2007.

Tesouro Nacional. Sistema de Informações Contábeis e Fiscais do Setor Público Brasileiro. Disponível em: $<$ https://siconfi.tesouro.gov.br/siconfi/pages/public/declaracao/ declaracao_list.jsf>. Acesso em: 01 jul. 2016.

Torvik, R. Why do some resource-abundant countries succeed while others do not? Oxford Review of Economic Policy, 25(2), 241-256, 2009.

Tubino, D.; Devlin, J. F.; Yap, N. A busca pela responsabilidade socioambiental em Itabira. In: Fernandes, F. R. C; Enríquez, M. A. R. da S; Alamino, R. de C. J. Recursos Minerais \& Sustentabilidade Territorial. v. I, Rio de Janeiro: CETEM/MCTI, 2011. cap. 13, p. 307-332.

Whitmore, A. The emperors new clothes: sustainable mining? Journal of Cleaner Production, 14(3-4), 309-314, 2006.

Yin, R. K. Estudo de caso: planejamento e métodos. Porto Alegre: Bookman, 2005. 